\title{
JAN KUČERA WINS \\ THE 2006 GEORGE HEVESY AWARD OF THE JOURNAL OF RADIOANALYTICAL AND NUCLEAR CHEMISTRY
}

The Editorial Board and the Publishers of the Journal of Radioanalytical and Nuclear Chemistry are glad to announce that the 2006 George Hevesy Medal has been awarded to Professor JAN KUČERA for his distinguished contributions to the Journal's filed.

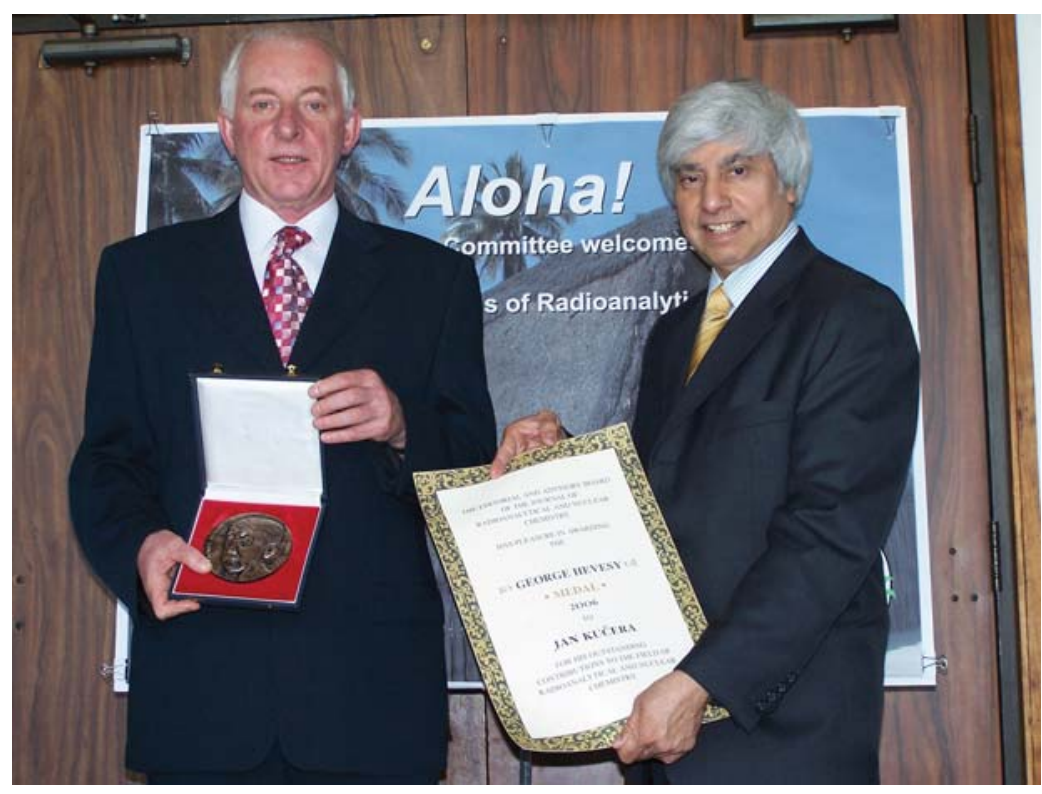

Professor JAN KUČERA

together with Professor AMARES CHATT, Chair of the Hevesy Selection Panel 